\title{
The Electrochemical Dissolution Characteristics of GH4169 Nickel Base Super Alloy in the Condition of Electrochemical Machining
}

\author{
Yu Tang, Zhengyang $X u^{*}$
}

College of Mechanical and Electrical Engineering, Nanjing University of Aeronautics and Astronautics, Nanjing, 210016, China

*E-mail: xuzhy@nuaa.edu.cn

doi: $10.20964 / 2018.01 .75$

Received: 27 June 2017 / Accepted: 18 November 2017 / Published: 16 December 2017

The nickel-based super-alloy of GH4169 is often used for manufacturing core functional components of turbo-machinery systems. It is a kind of high temperature, high specific strength and wear-resistant material, and machining this material by the use of conventional means is difficult. Electrochemical machining (ECM) is an effective method to machine GH4169 alloys but the electrochemical dissolution characteristics of GH4169 under ECM conditions are different from those measured by conventional electrochemical measurements. This study focuses on the electrochemical dissolution characteristics of GH4169 under ECM conditions. The open circuit potential, electrochemical impedance spectrum (EIS) and anodic polarization curve are investigated. The polarization curves were measured using an electrochemical workstation and corresponding equations were obtained by computer fitting. In addition, a formula for the electrochemical polarization resistance and the peak phase of alternating-current impedance's Bode diagram is deduced, and surface defects arising from unsteady flow in different electrolyte are compared.

Keywords: Electrochemical machining; GH4169; Electrochemical dissolution

\section{$\underline{\text { FULL TEXT }}$}

(C) 2018 The Authors. Published by ESG (www.electrochemsci.org). This article is an open access article distributed under the terms and conditions of the Creative Commons Attribution license (http://creativecommons.org/licenses/by/4.0/). 